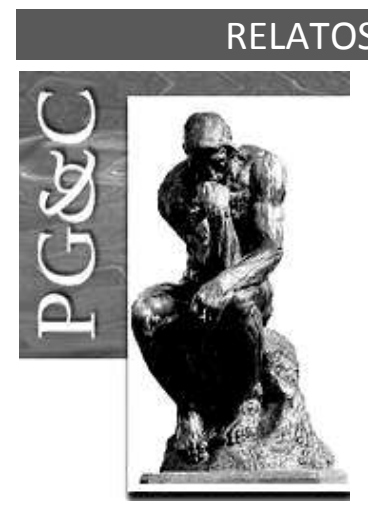

\title{
GESTÃO DO CONHECIMENTO E COMUNIDADE DE PRÁTICA NA CIÊNCIA DA INFORMAÇÃO: UMA ANÁLISE NA PRODUÇÃO CIENTÍFICA INDEXADA NA BRAPCI
}

\author{
Suzana de Lucena Lira \\ Doutora em Ciência da Informação pela Universidade Federal da Paraíba, \\ Brasil. \\ E-mail: suzanallira@hotmail.com \\ Edivânio Duarte de Souza \\ Doutor em Ciência da Informação pela Universidade Federal Minas Gerais, \\ Brasil. Professor da Universidade Federal de Alagoas, Brasil. \\ E-mail: edivanio.duarte@ichca.ufal.br \\ Edcleyton Bruno Fernandes da Silva \\ Doutorando em Ciência da Informação pela Universidade Federal Minas \\ Gerais, Brasil. \\ E-mail: biblioebfs@yahoo.com.br \\ Gabriella Domingos de Oliveira \\ Doutoranda em Ciência da Informação pela Universidade Federal da \\ Paraíba, Brasil. \\ E-mail: gabryellaholiveira@gmail.com
}

\begin{abstract}
Resumo
A gestão do conhecimento é compreendida como um macroprocesso que requer, principalmente, o estabelecimento de condições colaborativas destinadas à criação, ao compartilhamento e ao uso do conhecimento. A comunidade de prática apresenta-se como estratégia de gestão do conhecimento no campo da ciência da informação. Nessa perspectiva, objetiva analisar a produção científica a respeito de comunidade de prática como estratégia adotada na gestão do conhecimento. Trata-se de uma pesquisa exploratório-descritiva, desenvolvida a partir de uma abordagem qualitativa e quantitativa e operacionalizada por meio de levantamento bibliográfico na Base de Dados em Ciência da Informação (BRAPCI), com período de cobertura de 2009 a 2019. Os resultados apontam que a temática comunidade de prática está em pleno desenvolvimento, com abordagens em organizações de diversos setores. Esse crescimento na produção científica contribui com o fortalecimento da gestão do conhecimento e a evolução na área da Ciência da Informação.
\end{abstract}

Palavras-chave: Comunidade de prática. Gestão do conhecimento. Ciência da informação. Produção científica.

\section{KNOWLEDGE MANAGEMENT AND COMMUNITY OF PRACTICE IN INFORMATION SCIENCE}

\begin{abstract}
Knowledge management is understood as a macroprocess that requires, mainly, the establishment of collaborative conditions for the creation, sharing and use of knowledge. The community of practice presents itself as a knowledge management strategy in the field of information science. From this perspective, it aims to analyze the scientific production about community of practice as a strategy adopted in knowledge management. This is an exploratory-descriptive research, developed from a
\end{abstract}

Perspectivas em Gestão \& Conhecimento, João Pessoa, v. 10, número especial, p. 88-107, mar. 2020. DOI: http://dx.doi.org/10.21714/2236-417X2020v10nep88

http://periodicos.ufpb.br/ojs2/index.php/pgc. ISSN: 2236-417X. Publicação sob Licença (cc) EY-NC-ND 
qualitative and quantitative approach and operationalized through a bibliographic survey in the Information Science Database (BRAPCI), with coverage period from 2009 to 2019. The results indicate that the thematic community of practice is in full development, with approaches in organizations from various sectors. This increase in scientific production contributes to the strengthening of knowledge management and the evolution in the area of Information Science.

Keywords: Community of practice. Knowledge management. Information science. Scientific production.

\section{INTRODUÇÃO}

A gestão do conhecimento $(\mathrm{GC})$ surge da percepção de que o conhecimento produzido pelas pessoas em uma organização pode ser aproveitado e aumentado quando postas a desenvolvê-lo de forma colaborativa. Compartilhar o conhecimento organizacional corresponde a um processo que se verifica de forma contínua e interativa entre os sujeitos e coletivamente. A gestão do conhecimento tem o condão de demonstrar a importância que existe em construir e compartilhar o conhecimento organizacional. $O$ gestor estimula 0 interesse na aprendizagem e na inovação, promovendo uma cultura de compartilhamento do conhecimento em uma instituição, criando um ambiente favorável à construção de conhecimento e ao desenvolvimento de comunidade de prática.

A organização e a manutenção de comunidades de prática (CoP) configuram-se uma estratégia da gestão de conhecimento, principalmente, porque fomenta a cultura de compartilhamento de conhecimentos. Essas organizações sociais são formadas por grupos de pessoas com interesse em área comum, que por meio presencial ou virtual, podem expor ideias e experiências, partilhar problemas e encontrar soluções conjuntas. Com efeito, essas organizações são essenciais para a colaboração, o compartilhamento e, em última análise, a gestão do conhecimento, uma vez que, conforme Souza (2015), além de o conhecimento se apresentar como principal fonte de criação, inovação e competitividade, cria-se nesse contexto dinâmico um nexo recursivo entre informação, conhecimento, tecnologia e inovação.

A relação entre gestão do conhecimento e comunidade de prática parece ser um domínio epistemológico bastante estratégico para a compreensão e a prática desses macroprocessos no campo da ciência da informação. Partindo-se desse entendimento, a presente discussão tem como referência o seguinte questionamento: como se configura a produção intelectual no campo da Ciência da Informação que contempla a relação entre "gestão do conhecimento" e "comunidade de prática"? E, de modo mais preciso, em que medida a comunidade de prática vem sendo pensada como domínio estratégico para implementação da gestão do conhecimento?

Nessa perspectiva, a análise da produção científica da Ciência da Informação, que contemplem a comunidade de prática como tendência de estudos e de práticas de efetivação da gestão do conhecimento nas organizações, constitui o interesse de vislumbrar a evolução e as contribuições destas no desenvolvimento da área. Para Lira et al. (2017) a colaboração visível na produção científica configura-se como um importante espaço de debates de ideias em busca de um nivelamento entre áreas do conhecimento, que envolve indivíduos com formações plurais e titulações variadas.

Assim, o presente artigo objetiva analisar a produção científica a respeito de comunidade de prática, como vertente da gestão do conhecimento nas bases de periódicos científicos da Ciência da Informação no período de 2009 a 2019, correspondente a 10 anos de publicação da temática.

Encontra-se dividido em seis seções para melhor estruturá-lo. Após esta introdução, segue a fundamentação teórica com o desenvolvimento da perspectiva da gestão do

Perspectivas em Gestão \& Conhecimento, João Pessoa, v. 10, número especial, p. 88-107, mar. 2020. 
conhecimento na ciência da informação. Discute-se, em seguida, a comunidade de prática como uma estratégia para a dinâmica da gestão do conhecimento, bem como a sua inserção na literatura da área de ciência da informação. Em seguida, descrevem-se os procedimentos metodológicos adotados na realização da pesquisa, prosseguindo com os resultados e discussões, tomando como referências os fundamentos teórico-metodológicos adotados. E, por último, apresentam-se as conclusões, seguidas das referências utilizadas no texto, bem como o Apêndice A com as referências do corpus da pesquisa.

\section{A GESTÃO DO CONHECIMENTO NA CIÊNCIA DA INFORMAÇÃO}

Nesta discussão, tomando como principal referência Brookes (1980), a Ciência da Informação define seu domínio teórico na relação entre o Mundo 2 e o Mundo 3 de Popper (1999) que correspondem, respectivamente, ao mundo do conhecimento humano subjetivo ou estados mentais e ao mundo do conhecimento objetivo ou produtos da mente humana ${ }^{1}$.

O fato é que, para Brookes (1980), o espaço da inter-relação entre esses dois mundos ainda não havia sido reclamado por qualquer outra disciplina, havendo a possibilidade de a Ciência da Informação estabelecer um domínio disciplinar próprio, diferenciando-se inclusive dos domínios disciplinares da Biblioteconomia e da Documentação, mas se configurando, em certa medida, como uma extensão destes, que se encontram no Mundo 3 de Popper.

Em sua redefinição, Saracevic (1996, p. 60) esclarece:

[...] não importa se a atividade que trata dessas questões seja chamada de $\mathrm{Cl}$, informática, ciências da informação, estudos de informação, ciências da computação e da informação, inteligência artificial, ciência da informação e engenharia, biblioteconomia e ciência da informação, ou qualquer outra forma, desde que os problemas sejam enfocados em termos humanos e não tecnológicos.

Então, o enfoque atribuído pelo autor à Ciência da Informação é que os problemas informacionais sejam resolvidos pela esfera humana e não tecnológica. A tecnologia é facilitadora da comunicação, mas é no aspecto cognitivo que se processa e desenvolve-se a informação útil. A informação só se apresenta como tal quando dotada de significação. Ela é transmitida por algum suporte, mas, por meio da linguagem utilizada, permite que o receptor atribua-Ihe algum significado, tornando-se assim, informação, como aquilo que foi entendido.

Informação foi definida por Araújo (2014) como um conceito mais amplo, voltado para a dimensão cognitiva, como algo associado à interação entre dados (aquilo que existe materialmente) e conhecimento (aquilo que está na mente dos sujeitos), e seu estudo relacionado à identificação de significados e de interpretações. O autor em 2018 ao tratar das abordagens contemporâneas da Ciência da Informação, considera os estudos da cultura organizacional uma das teorias mais significativas para evolução do conceito de informação. Argumenta que a informação no ambiente organizacional não existe isoladamente nos

\footnotetext{
${ }^{1}$ O filósofo moderno Sir Karl Popper supera as visões monista e dualistas do mundo e propõe uma visão tripartida do mundo. 0 Mundo 1 compreende os aspectos físicos ou objetivos do mundo, o Mundo 2, todo o conhecimento humano subjetivo ou estados mentais, e, por sua vez, o Mundo 3 , todo o pensamento humano incorporado em artefatos, tais como artes, documentos, linguagens, músicas e tecnologias, entre outros. É importante considerar que, embora independentes, esses mundo interagem. A proposta deste filósofo tem como fundamento a necessidade de superação da teoria subjetivista do conhecimento, que para ele se apresenta como um erro tradicionalmente cometido, mas que deve dar lugar à teoria do conhecimento objetivo. (POPPER, 1999).
}

Perspectivas em Gestão \& Conhecimento, João Pessoa, v. 10, número especial, p. 88-107, mar. 2020. 
sujeitos, mas em comum nas atividades cotidianas, os quais agem de maneira recíproca, com "uma forma própria de lidar com a informação que é partilhada" (ARAÚJO, 2018, p. 68).

Ao discutir as possibilidades e as condições do conhecimento, Souza (2015) pautado na Teoria do Conhecimento, procura considerar a complexidade contemporânea das noções de "informação" e "conhecimento", mais amplas e flexíveis, bem como das relações dinâmicas que as envolvem naquele macroprocesso. Nesse contexto, merece destacar que, para o autor, as condições materiais tanto da informação quanto do conhecimento estabelecem-se na relação mente-mundo, ou seja, ao superar a tradição cartesiana, constata-se que os processos de informação (informar-se) e conhecimento (conhecer) ocorrem em espaços de significação social e historicamente construídos. Assim, a gestão da informação e a gestão do conhecimento assumem uma perspectiva de continuum gerencial e têm como fundamento as condições materiais que as constituem. É justo dizer que informação e conhecimento têm atributos que os diferenciam e os inter-relacionam recursivamente. ${ }^{2}$

Existem, pelo menos, duas visões do conhecimento organizacional que importa serem aqui destacadas, "cognitiva" e "construtivista". Nakano e Fleury (2005) evidenciam uma visão "cognitiva", em que o conhecimento é visto como "insumo", mesmo que seja intangível e complexo, mas que pode ser armazenado, combinado e reutilizado. À vista disso, gestão do conhecimento aproxima-se da gestão do processo produtivo de um bem intangível (o novo conhecimento). Na visão do "conhecimento como processo", a criação é resultado da interação pessoal, "construtivista", das relações interpessoais, em que a gestão do conhecimento é direcionada às pessoas, interações e comunicações interpessoais.

Para Bettencourt e Cianconi (2012, p. 3), o termo gestão pode ser compreendido como um processo, que consiste em administrar, orientar, conferir e avaliar ações e atividades de um determinado grupo ou instituição, com a finalidade de alcançar objetivos específicos.

Em uma perspectiva mais ampla, Duarte, Lira e Lira $(2014$, p. 269) reconhecem que a "[...] gestão é muito mais do que simplesmente administrar, gerir, conduzir [...]", na medida em que consideram também o ato ou efeito de fazer com que as pessoas compartilhem atividades, obrigações e competências que façam parte da vida das organizações às quais pertençam, sem impor algum tipo de ordem sobre o conhecimento.

A gestão do conhecimento tem como fundamento a construção de condições para o estabelecimento de uma cultura organizacional orientada ao compartilhamento, à colaboração, à produção e ao uso de dados, informação e conhecimento, em uma rede complexa, dinâmica e recursiva, por uma determinada comunidade.

Gutierrez (2008) afirma que gerir o conhecimento é muito mais difícil que a informação, já que o conhecimento implica, essencialmente, as pessoas e os complexos processos internos cognitivos, como a assimilação, a análise e a aprendizagem.

Em uma perspectiva teórico-prática sobre a gestão da informação e do conhecimento, Souza, Dias e Nassif (2011) defendem que a gestão do conhecimento no domínio da Ciência da Informação encontra-se na relação mente-mundo, onde se dá o processo de conhecer. Complementarmente, buscam assegurar que os processos de "informar-se" e "conhecer" estão localizados em domínios teórico-práticos muito próximos, onde se estabelece a relação entre informação e conhecimento. Nessa proposta, há relativa escala de compreensão,

\footnotetext{
${ }^{2}$ Souza (2015) considera que, ao discutir sobre as possiblidades de gestão de conhecimento, não se pode perder de vista a longa história dos estudos sobre o conhecimento, em sentido amplo, que envolve desde as fontes às condições neurocerebrais e socioculturais. É importante conhecer as particularidades que caracterizam as correntes de pensamento e, a partir delas, reconhecer as possibilidades, as condições e os desafios dos diferentes processos que envolvem o conhecimento, em sentidos amplo e restrito. Em última análise, considera que o conhecimento é socialmente construído, o que certamente redimensiona os diferentes posicionamentos acerca da gestão.
}

Perspectivas em Gestão \& Conhecimento, João Pessoa, v. 10, número especial, p. 88-107, mar. 2020. 
apreensão e representação da realidade que vai do menos ao mais complexo, ou seja, os dados da realidade são insumos para produção de informações e conhecimento e, aquelas por sua vez, são insumos para geração de conhecimentos.

Valentim (2008) explica que a gestão do conhecimento abrange um conjunto de atividades que objetiva trabalhar tanto a cultura organizacional, quanto a informacional, bem como a comunicação informacional/organizacional nos ambientes das instituições, com a intenção de promover um ambiente que favoreça a criação, a apreensão, o compartilhamento e a utilização do conhecimento.

Para Teixeira Filho $(2002$, p. 3) "[...] gerir conhecimento não é só administrar documentos ou lidar com sistemas informatizados. Faz parte também cuidar do compartilhamento de experiências e conhecimentos adquiridos entre os membros da organização [...]".

Sendo assim, a gestão do conhecimento visa promover os ambientes organizacionais para haver o compartilhamento de conhecimentos e experiências dos sujeitos que os compõem. Uma das possibilidades é incentivar a criação de comunidades de prática nesses ambientes. Trata-se, nas palavras de Souza (2015), do estabelecimento de uma cultura de compartilhamento orientada à construção de inteligentes coletivos.

\section{COMUNIDADE DE PRÁTICA COMO ESTRATÉGIA DA GESTÃO DO CONHECIMENTO}

O conhecimento está presente nas organizações, tanto nas conversas informais antes ou depois de reuniões, quanto no horário de parada para o cafezinho, nos ambientes de encontros espontâneos ou no happy hour após o expediente. A partir do estabelecimento de uma cultura de compartilhamento, todos esses momentos passaram a ser valorizados porque se percebeu que nestes surgem muitas condições potencializadoras à criação e ao compartilhamento de dados, informações e conhecimentos.

A gestão do conhecimento por meio de práticas, de modelos e da promoção de ambientes propícios ao compartilhamento demonstra que as organizações podem ser beneficiadas, uma vez que componentes dos conhecimentos existentes mesmo individualmente, quando socializados, tornam-se conhecimento organizacional e promovem seu acréscimo. Portanto, ao deixarem a organização, os sujeitos têm partilhado uma fração de seu conhecimento e levam consigo experiências vividas na organização com acréscimo do seu conhecimento individual.

Ademais, complementarmente, os artefatos, de modo amplo, são carregados de modelos mentais, lógicos e teóricos. Eles se apresentam como uma extensão dos processos de conhecimento. A obtenção de conhecimento não se dá de forma isolada do mundo e dos demais sujeitos, numa perspectiva dualista entre sujeito pensante e mundo objetivo, conforme a filosofia cartesiana. Há constantes interações entre mente e mundo externo que se manifestam na relação entre conhecimento e ação. (SOUZA, 2015, p. 41-42).

A comunidade de prática torna-se uma excelente estratégia a ser utilizada na gestão do conhecimento, para que os conhecimentos dos sujeitos sejam compartilhados na organização, de modo que Ihes possibilitem trocar experiências, levantar problemas comuns para encontrar soluções conjuntas, buscar inovação, promover acesso a boas práticas e conteúdos que podem servir de modelo para os demais membros do grupo.

Os primeiros autores a falar de Comunidades de Prática foram Lave e Wenger (1991), quando trataram da Teoria da Cognição Situada (TCS), que parte de uma perspectiva de que o

Perspectivas em Gestão \& Conhecimento, João Pessoa, v. 10, número especial, p. 88-107, mar. 2020. 
ser humano vive experiências pessoais, possui estrutura e história individual, mas que permanece em contínua interação com outras pessoas, em diversas situações e espaços, experienciando emoções e linguagens. A aprendizagem, portanto, é uma relação social na medida em que está na relação entre o sujeito e o mundo social em que vive. Os autores conceituaram comunidades de prática como grupos de pessoas que compartilham uma preocupação, um conjunto de problemas ou uma paixão por uma temática, e que aprofundam seus conhecimentos e especialização nessa área pela interação numa base continuada.

Para Teixeira Filho (2002, p. 163), comunidade de prática é um "grupo de pessoas ligadas primariamente por interesses em comum, que compartilham conhecimentos e experiências adquiridos em sua prática de trabalho e/ou pessoal".

O estabelecimento de uma comunidade de prática promove a cultura de compartilhamento e a constituição de inteligentes coletivos essenciais à colaboração, ao aprendizado e ao desenvolvimento de competências em informação e conhecimento. ${ }^{3}$ Por esse horizonte, Álvares (2010) define a comunidade de prática como um grupo de pessoas que possuem problemas, que possam expor acerca de uma temática de interesse dos demais membros e que desenvolvem conhecimento em determinada área, com interação, para se alcançar objetivo comum.

Para Garcia (2005), as comunidades de prática estão relacionadas ao trabalho, por serem compostas por grupo de pessoas que se conectam em torno de assunto de interesse comum, com o objetivo de aprender e de ensinar. Esse tipo de grupo estabelece fortes ligações, pois estão presentes nos participantes a confiança e o companheirismo, bases imprescindíveis ao funcionamento da comunidade. Neste escopo teórico-conceitual, a comunidade de prática é, na perspectiva de Souza $(2015$, p. 46), um verdadeiro inteligente coletivo, que "[...] corresponde a um conjunto de pessoas que compartilhe experiências, as quais compreendem valores, compromissos, símbolos, significados, pontos de vista, aprendizados, competências, informação, e, por conseguinte, conhecimento".

Lira (2019, p. 219) define comunidade de prática como "grupo de pessoas que possuem interesse comum, que compartilham preocupações e problemas por meio presencial ou virtual, que confiam uns aos outros os assuntos inerentes às suas atividades, para interação e resolução de questões em conjunto, bem como expõem ideias e práticas relacionadas ao contexto da comunidade".

É também forçoso considerar, a partir de Teixeira Filho (2002), que as bases de conhecimento geradas em comunidades de prática são complexas e extensas. Ocorre que as organizações devem estabelecer constantemente condições e meios de incentivo à contribuição espontânea e ao compartilhamento de conhecimentos por parte dos colaboradores.

Duarte et al. (2019, p. 17) salientam que "[...] para manter uma CoP ativa deve-se pensar na sua evolução, manter o diálogo, desenvolver um ambiente para compartilhamento e promover uma cultura favorável para engajamento e relações interpessoais". Portanto, formar uma comunidade de prática pode até parecer simples, porém, deve-se procurar mantê-la ativa, enquanto seus membros perceberem a importância do engajamento, da troca, do pertencimento, da participação e do compartilhamento.

Lira (2019, p. 217-218) propõe:

\footnotetext{
${ }^{3}$ Na proposta teórico-metodológica de Souza, Dias e Nassif (2011), a gestão da informação e do conhecimento tem como bases a cultura organizacional e as práticas organizacionais e como componentes os conteúdos, as pessoas e as tecnologias. As complexas e diversas relações entre as condições e os componentes resultam em estágios, processos e produtos diferenciados relacionados a dados da realidade, informações e conhecimento.
}

Perspectivas em Gestão \& Conhecimento, João Pessoa, v. 10, número especial, p. 88-107, mar. 2020. 
O desenvolvimento de uma CoP requer adequações para o grupo que está sendo idealizado, uma vez que foram evidenciados na pesquisa que os membros devem sentir-se comprometidos para colaborar com os demais; perceber identidade de problemas para vislumbrar soluções conjuntas; possuir confiança nos integrantes para haver trabalho colaborativo; ampliar a participação por meio de incentivo aos colegas da equipe local, que possa agregar adeptos e mais conhecimento; reconhecer a união e o interesse dos participantes para ajudar na resolução de problemas; contribuir com o compartilhamento de conhecimentos; e manter a interação alinhada com os objetivos do grupo.

A autora relata que a participação em uma comunidade de prática parte do interesse das pessoas em se engajarem no grupo por identidade com o contexto e pela confiança nos demais membros por meio da contribuição coletiva para resolução de problemas, reconhecendo a união e o compartilhamento de conhecimentos, bem como requer manter a interação e a conexão de objetivos comuns.

A gestão do conhecimento como disciplina, que contribui com suas estratégias e práticas nas organizações e com uma produção científica relevante, evidencia a comunidade de prática como uma de suas estratégias que mais proporcionam o entrelaçamento de saberes, uma vez que possui o condão de praticar o compartilhamento de conhecimentos.

\section{PROCEDIMENTOS METODOLÓGICOS}

A pesquisa parte do pressuposto teórico-metodológico de que a temática comunidade de prática tem sido explorada na área da Ciência da Informação, sobretudo nas pesquisas que abordam a Gestão do Conhecimento, e tem contribuído para o compartilhamento de informação e conhecimento. Assim, do ponto de vista dos objetivos, caracteriza-se como uma pesquisa exploratório-descritiva, fundamentada numa abordagem quanti-qualitativa.

Dos procedimentos, a pesquisa tem como base um estudo bibliográfico realizado na Base de Dados em Ciência da Informação (BRAPCI), que indexa produções e comunicações científicas do campo da Ciência da Informação. A escolha da BRAPCI deveu-se ao fato de ela possibilitar uma visão do conjunto da produção científica da área de Ciência da Informação acerca da temática comunidade de prática, bem como da possibilidade de delimitação no escopo da inter-relação com a gestão do conhecimento. Entende-se, portanto, que esta se constitui uma importante fonte de informação para a pesquisa.

Para Targino (2000, p. 10) "é a comunicação científica que favorece ao produto (produção científica) e aos produtores (pesquisadores) a necessária visibilidade e possível credibilidade no meio social em que produto e produtores se inserem".

Quanto à qualidade dos artigos e de outros tipos de produção, recorreu-se à avaliação Qualis-Periódicos, que é uma ferramenta usada para classificar a produção científica dos programas de pós-graduação (PLATAFORMA SUCUPIRA). Para a presente pesquisa, foi realizado um levantamento do Qualis dos periódicos em que foram publicados os artigos veiculados sobre a temática.

Do ponto de vista temporal, definiu-se como recorte o período de 10 anos, ou seja, foram levantados os artigos científicos e as comunicações de eventos publicados entre os anos de 2009 e 2019. O levantamento foi realizado com a inserção dos termos de busca "comunidade de prática" e "comunidades de prática" no campo de metadados destinado à recuperação de publicações, considerando, além do período, os seguintes delimitadores: título, palavra-chave e resumo.

Perspectivas em Gestão \& Conhecimento, João Pessoa, v. 10, número especial, p. 88-107, mar. 2020. 
Os critérios de inclusão utilizados na pesquisa foram as comunicações encontradas que continham, no título, subtítulo, resumo ou palavras-chave, os elementos que apontassem o artigo como pertinente ao tema comunidade de prática. Como critérios de exclusão foram retirados da pesquisa os artigos que não abordassem o tema objeto deste trabalho e que não evidenciassem a comunidade de prática no contexto da gestão do conhecimento.

No primeiro levantamento, obtiveram-se 90 publicações, entre artigos científicos e comunicações de eventos. A partir desse resultado, realizaram-se pré-análises de títulos, resumos e palavras-chave das publicações recuperadas, buscando refinar a pesquisa e dar maior qualidade aos resultados obtidos.

Ao estabelecer a relação dos termos de busca com a gestão de conhecimento, contemplando coerência com a pesquisa, restaram 21 produções que refletem nos títulos, nas palavras-chave e/ou nos resumos, a delimitação da pesquisa, que é a abordagem de comunidade de prática no âmbito da gestão do conhecimento. Porém, como permaneceram dúvidas em relação aos demais textos recuperados, foi necessário analisá-los também para se perceber o enfoque atribuído aos artigos. A partir dessa análise, foram identificadas mais quatro produções que tratam da abordagem de comunidade de prática na relação com a gestão do conhecimento na Ciência da Informação, compondo o corpus da pesquisa, 25 produções, entre artigos científicos e comunicações científicas, indexados na BRAPCl, conforme Apêndice A.

Foi realizada também uma análise quanto à autoria e coautoria das publicações na área, pelo que foi utilizada a análise de redes sociais. A colaboração entre autores é importante para se perceber o compartilhamento de conhecimentos, e, para Duarte $(2015, \mathrm{p}$. 143) "somente quando se postula uma forma específica de conexão entre indivíduos, instituições, comportamentos e redes é que se podem gerar proposições testáveis".

Para essa construção, foi elaborada uma matriz de colaboração em coautoria utilizando-se o software Excell, desenvolvida para alimentar a ferramenta Ucinet, resultando nas redes de cooperação entre os diversos autores e coautores porventura existentes.

Após essas análises, as publicações classificadas dentro do escopo da pesquisa foram sistematizadas em quatro categorias, a saber, autoria, ano de publicação, fonte de publicação (periódico científico ou anais de evento) e título da publicação (artigo científico ou comunicação científica). Esta categorização permitiu estabelecer relações nas análises da produção e construir um conjunto de indicadores acerca das categorias analíticas.

\section{RESULTADOS E DISCUSSÕES}

Preliminarmente, é importante pontuar que, de modo geral, a temática "comunidade de prática" é consideravelmente estudada na Ciência da Informação, tomando como referência as diferentes categorias analíticas como, por exemplo, ano de publicação, autoria, fonte de informação e temáticas a elas relacionadas, como pode ser observado no Quadro 1. Além dos artigos científicos, a BRAPCl indexa atualmente as comunicações publicadas em eventos técnico-científicos. No ano de 2019, no XX Encontro Nacional de Pesquisa em Ciência da Informação (ENANCIB) foram publicadas duas comunicações relacionadas à temática que é aqui objeto de estudo. Do total, duas referem-se a comunicações de eventos e 23 a artigos científicos, no período compreendido entre 2009 e 2019.

Quadro 1 - Produção sobre comunidade de prática indexada na BRAPCI

\begin{tabular}{|c|c|l|l|}
\hline AUTORIA & ANO & PUBLICAÇÃO & ARTIGO/COMUNICAÇÃO \\
\hline SOUSA, C.; SOUZA, E. & 2019 & Em Questão & Comunidades de prática: aprendizado e \\
\hline
\end{tabular}

Perspectivas em Gestão \& Conhecimento, João Pessoa, v. 10, número especial, p. 88-107, mar. 2020. 


\begin{tabular}{|c|c|c|c|}
\hline & & & $\begin{array}{l}\text { compartilhamento de conhecimento entre } \\
\text { trabalhadores nas organizações }\end{array}$ \\
\hline $\begin{array}{lll}\text { LLARENA, } & \text { M. A, A.; } \\
\text { LLARENA, } & \text { R. A. S.; } \\
\text { DUARTE, E. N.; LIRA, S. } \\
\text { L.; FEITOZA, R. A. B. }\end{array}$ & 2019 & XX ENANCIB & $\begin{array}{l}\text { Construção do conhecimento por meio da } \\
\text { aprendizagem colaborativa em } \\
\text { comunidade prática }\end{array}$ \\
\hline LIRA, S. L.; DUARTE, E. N. & 2019 & XX ENANCIB & $\begin{array}{l}\text { Comunidade de prática como estratégia } \\
\text { de Gestão do conhecimento na } \\
\text { contabilidade pública de Universidades } \\
\text { Federais do Brasil }\end{array}$ \\
\hline $\begin{array}{l}\text { MELO, E. S.; MORAES, } \\
\text { M. G.; COSTA, M. A. }\end{array}$ & 2019 & $\begin{array}{lr}\text { Perspectivas } & \text { em } \\
\text { Ciência } & \text { da } \\
\text { Informação } & \end{array}$ & $\begin{array}{l}\text { Características de comunidades de } \\
\text { prática existentes no Serviço de } \\
\text { Informação em Arte: o caso da } \\
\text { REDARTE/RJ }\end{array}$ \\
\hline RIANDE, G. R. & 2019 & Liinc em revista & $\begin{array}{l}\text { iÚnete! humanidades digitales y cultura } \\
\text { del asociacionismo | juntemo-nos! } \\
\text { humanidades digitais e cultura do } \\
\text { associacionismo | join us! digital } \\
\text { humanities and association culture. } \\
\end{array}$ \\
\hline CARVALHO, M. & 2018 & Cadernos BAD & $\begin{array}{l}\text { Recursos educacionais abertos na } \\
\text { universidade aberta. A rede como } \\
\text { estratégia de comunicação e } \\
\text { sustentabilidade }\end{array}$ \\
\hline $\begin{array}{l}\text { WILBERT, J.; } \\
\text { DANDOLINI, G.; STEIL, A. } \\
\text { V. }\end{array}$ & 2018 & $\begin{array}{lr}\text { Perspectivas } & \text { em } \\
\text { Gestão } & \& \\
\text { Conhecimento } & \end{array}$ & $\begin{array}{l}\text { Transformações conceituais de } \\
\text { comunidades de prática: da aprendizagem } \\
\text { situada à gestão organizacional }\end{array}$ \\
\hline $\begin{array}{l}\text { LIRA, S. L.; ARAÚJO, W. } \\
\text { J.; DUARTE, E. N. }\end{array}$ & 2017 & $\begin{array}{lr}\text { Perspectivas } & \text { em } \\
\text { Gestão } & \& \\
\text { Conhecimento } & \end{array}$ & $\begin{array}{l}\text { Cenários prospectivos para implantação } \\
\text { de comunidades de prática em unidades } \\
\text { de contabilidade em universidades } \\
\text { públicas }\end{array}$ \\
\hline $\begin{array}{l}\text { RIMÁ, J. C.; GARCIA, J. C. } \\
\text { R.; TARGINO, M. G. }\end{array}$ & 2017 & Informação em Pauta & $\begin{array}{l}\text { Comunidades de práticas virtuais dos } \\
\text { técnicos administrativos em educação de } \\
\text { Instituições de Ensino Superior }\end{array}$ \\
\hline FERRARI, E.; ASSIS, J. & 2017 & $\begin{array}{l}\text { Revista Brasileira de } \\
\text { Educação em Ciência } \\
\text { da Informação }\end{array}$ & $\begin{array}{l}\text { A dimensão informacional da transição } \\
\text { capilar: identidade e empoderamento nas } \\
\text { mídias sociais }\end{array}$ \\
\hline $\begin{array}{l}\text { FAQUETI, M. F.; ALVES, } \\
\text { J. B. M.; STEIL, A. V. }\end{array}$ & 2016 & $\begin{array}{lr}\text { Perspectivas } & \text { em } \\
\text { Ciência } & \text { da } \\
\text { Informação } & \\
\end{array}$ & $\begin{array}{l}\text { Aprendizagem organizacional em } \\
\text { bibliotecas acadêmicas: uma revisão } \\
\text { sistemática }\end{array}$ \\
\hline $\begin{array}{l}\text { MARCHIORI, P. Z.; } \\
\text { APPEL, A. L.; BETTONI, E. } \\
\text { M. }\end{array}$ & 2016 & $\begin{array}{l}\text { AtoZ: novas práticas } \\
\text { em informação e } \\
\text { conhecimento }\end{array}$ & $\begin{array}{l}\text { A disrupção pervasiva da tecnologia na } \\
\text { privacidade e nos processos de } \\
\text { aprendizagem }\end{array}$ \\
\hline $\begin{array}{l}\text { FERNANDES, F. R.; } \\
\text { CARDOSO, T. A.; } \\
\text { CAPAVERDE, L. Z; SILVA, } \\
\text { H. F. N. }\end{array}$ & 2016 & $\begin{array}{l}\text { AtoZ: novas práticas } \\
\text { em informação e } \\
\text { conhecimento }\end{array}$ & $\begin{array}{l}\text { Comunidades de prática: uma revisão } \\
\text { bibliográfica sistemática sobre casos de } \\
\text { aplicação organizacional }\end{array}$ \\
\hline $\begin{array}{l}\text { SCHMITT, S. R.; } \\
\text { PACHECO, A. S. V. }\end{array}$ & 2016 & Rev. P2P \& inov & $\begin{array}{l}\text { Fatores críticos de sucesso à manutenção } \\
\text { de comunidades de prática: análise sob a } \\
\text { ótica de um grupo de gestores com } \\
\text { características preponderantes de uma } \\
\text { comunidade }\end{array}$ \\
\hline MELO, E. S.; ALMEIDA, & 2015 & Informação@Profissõ & Comunidades de prática: um estudo de \\
\hline
\end{tabular}

Perspectivas em Gestão \& Conhecimento, João Pessoa, v. 10, número especial, p. 88-107, mar. 2020. 


\begin{tabular}{|c|c|c|c|}
\hline M. C. & & es & caso REDARTE/RJ \\
\hline $\begin{array}{l}\text { DE SOUSA, R.; BUFREM, } \\
\text { L.; DO NASCIMENTO, B. }\end{array}$ & 2015 & Em Questão & $\begin{array}{l}\text { Olhares complementares sobre } \\
\text { letramento científico e o papel dos } \\
\text { pesquisadores em comunidades virtuais }\end{array}$ \\
\hline $\begin{array}{l}\text { DRAGO, I.; SILVA, H. F. } \\
\text { N.; SATO, K. }\end{array}$ & 2014 & Em Questão & $\begin{array}{l}\text { Contribuições do movimento Nós } \\
\text { Podemos Paraná para a criação e } \\
\text { compartilhamento de conhecimentos }\end{array}$ \\
\hline $\begin{array}{l}\text { DE BEM, R.; AMBONI, N. } \\
\text { F. }\end{array}$ & 2013 & $\begin{array}{l}\text { Revista ACB: } \\
\text { Biblioteconomia em } \\
\text { Santa Catarina }\end{array}$ & $\begin{array}{l}\text { Práticas de gestão do conhecimento: o } \\
\text { caso da biblioteca universitária da UFSC }\end{array}$ \\
\hline $\begin{array}{l}\text { SILVA, H. F. N.; ARBOIT, } \\
\text { A. E.; GARCIA, A. K.; } \\
\text { RIGONI, C. F. }\end{array}$ & 2012 & $\begin{array}{l}\text { Perspectivas em } \\
\text { Ciência da } \\
\text { Informação }\end{array}$ & $\begin{array}{l}\text { As contribuições relativas ao uso de } \\
\text { eventos/fóruns para constituição de } \\
\text { comunidades de práticas e expressão da } \\
\text { inteligência coletiva: o caso do } \\
\text { Bibliocontas }\end{array}$ \\
\hline $\begin{array}{l}\text { SARRUF, P. G.; SILVA, H. } \\
\text { F. N. }\end{array}$ & 2012 & $\begin{array}{l}\text { DataGramaZero - } \\
\text { Revista de } \\
\text { Informação }\end{array}$ & $\begin{array}{l}\text { Comunidades de prática virtuais e a troca } \\
\text { e criação de conhecimentos em micro e } \\
\text { pequenas empresas }\end{array}$ \\
\hline SILVA, A. M. N. H. & 2011 & $\begin{array}{l}\text { Informação \& } \\
\text { Sociedade }\end{array}$ & $\begin{array}{l}\text { Viabilidade de implementação de } \\
\text { Comunidades de Prática (COP) para a } \\
\text { gestão e compartilhamento da informação } \\
\text { na Biblioteca Central do UNIPÊ }\end{array}$ \\
\hline TAVARES, M. G. P. & 2011 & $\begin{array}{l}\text { Revista } \\
\text { iberoamericana de } \\
\text { educación }\end{array}$ & $\begin{array}{l}\text { Informação, aprendizagem e criação do } \\
\text { conhecimento em comunidades de } \\
\text { prática: um estudo de caso }\end{array}$ \\
\hline $\begin{array}{l}\text { BERNETT, D.; VARVAKIS, } \\
\text { G. J. }\end{array}$ & 2010 & $\begin{array}{l}\text { DataGramaZero - } \\
\text { Revista de } \\
\text { Informação }\end{array}$ & $\begin{array}{l}\text { Desafios das tecnologias de informação e } \\
\text { comunicação sob a perspectiva da gestão } \\
\text { do conhecimento na sociedade em redes }\end{array}$ \\
\hline $\begin{array}{l}\text { CORNÉLIO, N. A. G.; } \\
\text { ABREU, A. F.; COSTA, E. } \\
\text { O. }\end{array}$ & 2010 & $\begin{array}{l}\text { Ciência da } \\
\text { Informação }\end{array}$ & $\begin{array}{l}\text { Espaço interativo: modelo de relação } \\
\text { universidade-empresa baseada em } \\
\text { comunidades de prática }\end{array}$ \\
\hline MOURA, M. A. & 2009 & $\begin{array}{l}\text { DataGramaZero - } \\
\text { Revista de } \\
\text { Informação }\end{array}$ & $\begin{array}{l}\text { Informação e conhecimento em redes } \\
\text { virtuais de cooperação científica: } \\
\text { necessidades, ferramentas e usos. }\end{array}$ \\
\hline
\end{tabular}

Fonte: dados da pesquisa, 2019.

Os resultados da pesquisa evidenciam que as publicações e seus respectivos autores fazem parte do escopo da Ciência da Informação como pesquisadores, docentes e discentes vinculados a programas de pós-graduação pertencentes a diferentes instituições. Em relação ao conteúdo das produções, foi possível identificar que o mesmo propõe-se a problematizar e investigar a temática, para a construção de uma ciência evolutiva.

O artigo de Sousa e Souza (2019) publicado no periódico Em questão analisa em que medida a participação em uma comunidade de prática, como estratégia de gestão do conhecimento, pode apoiar o processo de aprendizagem de trabalhadores. Para Llarena et al. (2019), o entendimento sobre comunidade de prática e aprendizagem colaborativa culmina em contribuições para a construção do conhecimento dos atores sociais em ambientes colaborativos diversificados. Já Lira e Duarte (2019) consideram a comunidade de prática uma estratégia de gestão do conhecimento que promove o aprendizado, o compartilhamento e o desenvolvimento de pessoas que se integram em grupo. A gestão do conhecimento, nesse contexto, proporciona essa interação, por meio do favorecimento de ambientes propícios ao desenvolvimento do conhecimento.

Em seu artigo Melo, Moraes e Costa (2019) buscam identificar e analisar a existência

Perspectivas em Gestão \& Conhecimento, João Pessoa, v. 10, número especial, p. 88-107, mar. 2020. 
das principais características de comunidades de prática na Rede de Bibliotecas e Centros de Informação em Arte no Estado do Rio de Janeiro (REDARTE/RJ). Riande (2019) em seu artigo, trata da comunidade de prática como um lugar informal para encontro entre pessoas que compartilham interesses. Carvalho (2018) apresenta a comunidade de prática da Universidade Aberta (UAb) relativa à produção e disponibilização de recursos educacionais abertos.

O texto de Wilbert, Dandolini e Steil (2018) trata das transformações conceituais de comunidade de prática, partindo do conceito analítico da área de aprendizagem situada, para transformação em um conceito instrumental, onde se descobriu a utilidade do conceito para a aplicação na prática. O artigo de Lira, Araújo e Duarte (2017) demonstra o uso da informação estratégica para construção de cenários prospectivos no sentido de propor uma comunidade de prática para a área contábil de universidades públicas, como ferramenta para auxiliar na gestão do conhecimento.

Para Ferrari e Assis (2017), a troca de experiências e informações nas mídias sociais é considerada relevante como contexto que viabiliza a geração e a disseminação do conhecimento no âmbito das comunidades virtuais de prática. Rimá, Garcia e Targino (2017), por sua vez, exploraram em seu texto a gestão pública dos técnicos administrativos em educação à luz das comunidades de práticas virtuais, como um grupo que, ao se utilizar dessa estratégia, amplia e desenvolve conhecimentos entre os componentes oriundos de várias regiões e vinculados a diferentes Instituições de Ensino Superior (IES) brasileiras.

O artigo de Faqueti, Alves e Steil (2016) abordou as comunidades de prática como significativas para gerar e transferir conhecimentos. Marchiori, Appel e Bettoni (2016) relatam que os resultados de estudos consolidados apontam para as vantagens na adoção das comunidades de práticas, para a solução de problemas, a sinergia entre as unidades organizacionais e a geração de novas estratégias competitivas.

O artigo de Fernandes et al. (2016) trata das funções da gestão do conhecimento para as organizações, que identificam o conhecimento como um diferencial competitivo e estratégico de negócio. Os autores atribuem às comunidades de prática uma das iniciativas desse macro-processo, que contribui com a partilha de conhecimentos, a liderança exercida pelos integrantes e o alinhamento à estratégia organizacional, promovendo benefícios com $o$ desenvolvimento profissional dos membros, com a solução de problemas e com a economia de tempo.

Em sua pesquisa, Schmitt e Pacheco (2016) procuraram resgatar os fatores críticos de sucesso à manutenção das comunidades de prática e verificar suas aderências a um grupo de gestores que possui características preponderantes desse tipo de comunidade. Já Melo e Almeida (2015) procuraram identificar e analisar as características da Rede de Bibliotecas e Centros de Informação em Arte no Estado do Rio de Janeiro (REDARTE/RJ) para buscar semelhanças com as comunidades de prática e as possibilidades de estas contribuírem com a maior integração das ações desenvolvidas pelos profissionais de informação em arte e suas instituições. O texto de Sousa, Bufrem e Nascimento (2015) aborda o letramento científico e o papel dos pesquisadores em comunidades virtuais.

Drago, Silva e Sato (2014) em seu artigo, demonstram que o núcleo estudado pode ser considerado uma comunidade de prática na fase de maturidade, e os seus membros engajamse, criam e desenvolvem projetos comuns, renovando os interesses, o comprometimento e o relacionamento, tornando-se assim, referência na região do Paraná onde está inserido o núcleo, pelos seus resultados positivos. De Bem e Amboni (2013) apresentam as práticas de gestão do conhecimento realizadas na Biblioteca Universitária da Universidade Federal de Santa Catariana (UFSC), com vistas ao compartilhamento de conhecimento como comunidades de prática em diferentes áreas, com o intuito de compartilhar conhecimento e promover a aprendizagem pessoal e organizacional.

Perspectivas em Gestão \& Conhecimento, João Pessoa, v. 10, número especial, p. 88-107, mar. 2020. 
Silva et al. (2012) refletem sobre as comunidades de prática, na perspectiva do conceito de inteligência coletiva, e apontam os elementos encontrados nos fóruns virtuais e presenciais que podem contribuir para constituição dessa organização social, cujo resultado propicia a transformação das pessoas, a formação de identidades e a negociação de significados do fazer profissional.

No artigo publicado na revista DataGramaZero, Sarruf e Silva (2012) discutem sobre comunidades virtuais e sua relação com as comunidades de prática. Analisam as possibilidades de as comunidades virtuais que utilizam ferramentas colaborativas constituírem-se em comunidades de prática e contribuírem com o processo de troca e compartilhamento de conhecimentos no âmbito das micro e pequenas empresas. Silva (2011) argumenta que as comunidades de prática surgem como ferramenta que estimula o aprendizado, o compartilhamento de informações e o trabalho colaborativo entre grupos de trabalho e seus membros. Tavares (2011), em seu artigo investigou o funcionamento das comunidades de prática, considerando os seguintes aspectos: processamento da informação, aprendizagem e criação do conhecimento tácito.

Bernett e Varvakis (2010) refletem sobre questões de comunidade, no contexto da gestão do conhecimento e compreendem a comunidade de prática como um grupo de pessoas que se importam com um conjunto comum de questões, que compartilham e desenvolvem conhecimentos nesse domínio e, assim, organizam uma competência crítica para o sucesso da organização. Esses sujeitos são responsáveis pela fruição do conhecimento adquirido em diferentes núcleos dos sistemas organizacionais, agrupados normalmente pela conectividade positiva do sentido do trabalho e de seus objetos.

Cornélio, Abreu e Costa (2010) objetivaram desenvolver um modelo de relação entre universidades e empresas por meio de um ambiente presencial e virtual para promover a difusão da ciência, tecnologia e inovação, baseado no compartilhamento do conhecimento entre membros de uma comunidade de prática. O modelo estimula a construção do conhecimento a partir de tecnologias da Web 2.0, visando a promover o processo de transferência do conhecimento das instituições de ensino/pesquisa ao setor produtivo. $E$, no último artigo aqui analisado, Moura (2009) apresenta as concepções de comunidade de prática, comunidades virtuais de prática e redes sociais e o entrelaçamento na dinâmica de compartilhamento de informação e conhecimento.

Dentre os periódicos que mais publicaram acerca de comunidade de prática no campo da Ciência da Informação tem-se no Gráfico 1 a percentagem de publicação por fonte.

\section{Gráfico 1 - Indicadores de produção sobre CoP nos periódicos de Ciência da Informação no período de 2009 a 2019}

Perspectivas em Gestão \& Conhecimento, João Pessoa, v. 10, número especial, p. 88-107, mar. 2020. 


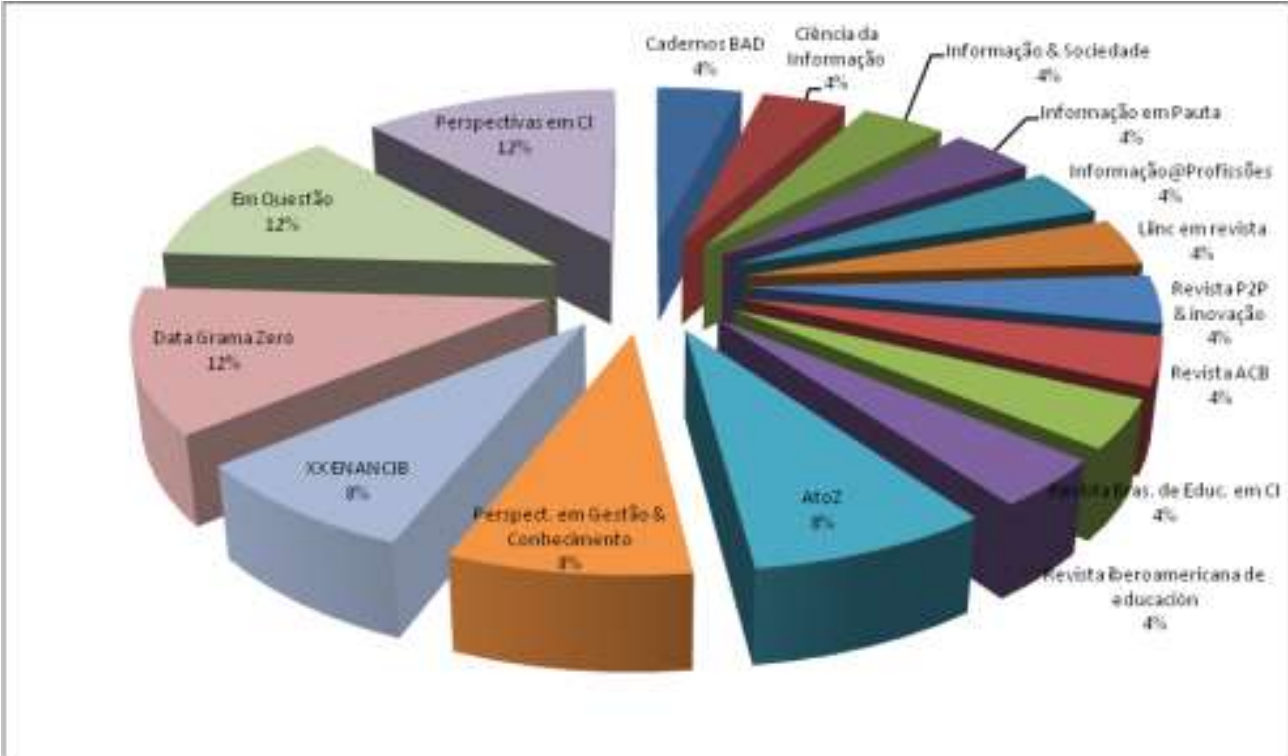

Fonte: Dados da Pesquisa, 2019.

Observa-se, no Gráfico 1, que os periódicos que mais publicaram acerca da comunidade de prática foram: DataGramaZero: Revista de Ciência da Informação; Em Questão; e Perspectiva em Ciência da Informação. É perceptível também o crescente número de publicações desses periódicos na temática, quando se relacionam à Pesquisa e à PósGraduação em Ciência da Informação, uma vez que dois desses periódicos pertencem a instituições que têm Programas de Pós-Graduação em Ciência da Informação, notadamente, a Em Questão (Revista do Programa de Pós-Graduação em Ciência da Informação da Universidade Federal do Rio Grande do Sul) e a Perspectivas em Ciência da Informação (Revista da Escola de Ciência da Informação da Universidade Federal de Minas Gerais).

Quanto ao Qualis das revistas que publicaram sobre a temática comunidade de prática, apresenta-se o gráfico 2 abaixo para melhor visualização:

\section{Gráfico 2 - Indicadores de Qualis dos periódicos que publicaram sobre CoP}

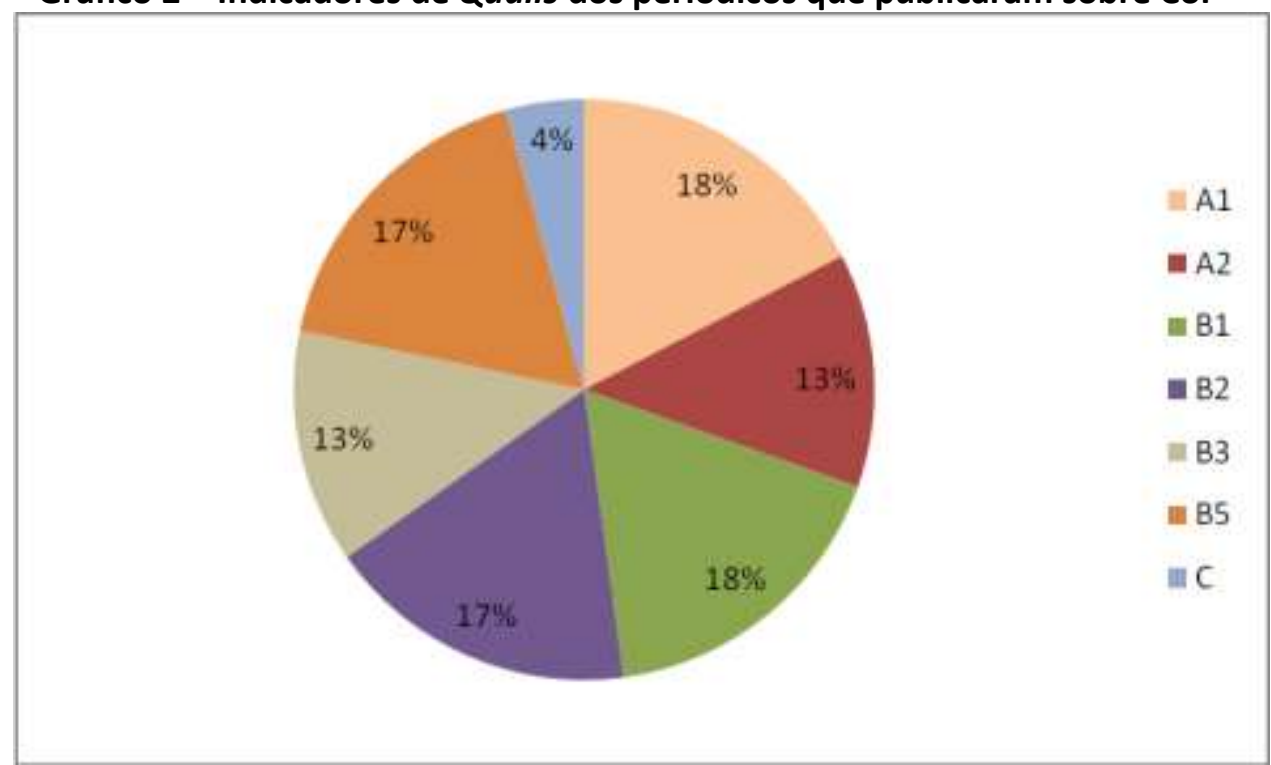

Fonte: Dados da Pesquisa, 2019.

Perspectivas em Gestão \& Conhecimento, João Pessoa, v. 10, número especial, p. 88-107, mar. 2020. 
Observa-se que as revistas que publicaram sobre a temática da pesquisa, foram em sua maioria, de Qualis A1 e B1, representando $36 \%$ do total das publicações. Seguidas pelas de Qualis B2 e B5, que representam 34\% dos artigos publicados. Tem-se 13\% das publicações em revistas de Qualis A2, assim como Qualis B3 e, por fim, apenas 4\% de publicação sobre comunidade de prática em revista de Qualis C.

No intervalo temporal de 10 anos de publicação sobre a temática comunidade de prática em publicações da Ciência da Informação, incluindo artigos científicos e comunicações científicas, pode-se observar no Gráfico 2, a evolução quantitativa de publicações nos últimos anos. De modo geral, observa-se um crescente número de publicações, exceto nos anos de 2013, 2014 e 2018, em relação aos anos imediatamente anteriores.

\section{Gráfico 2 - Indicadores anuais de publicações acerca de comunidade de prática}

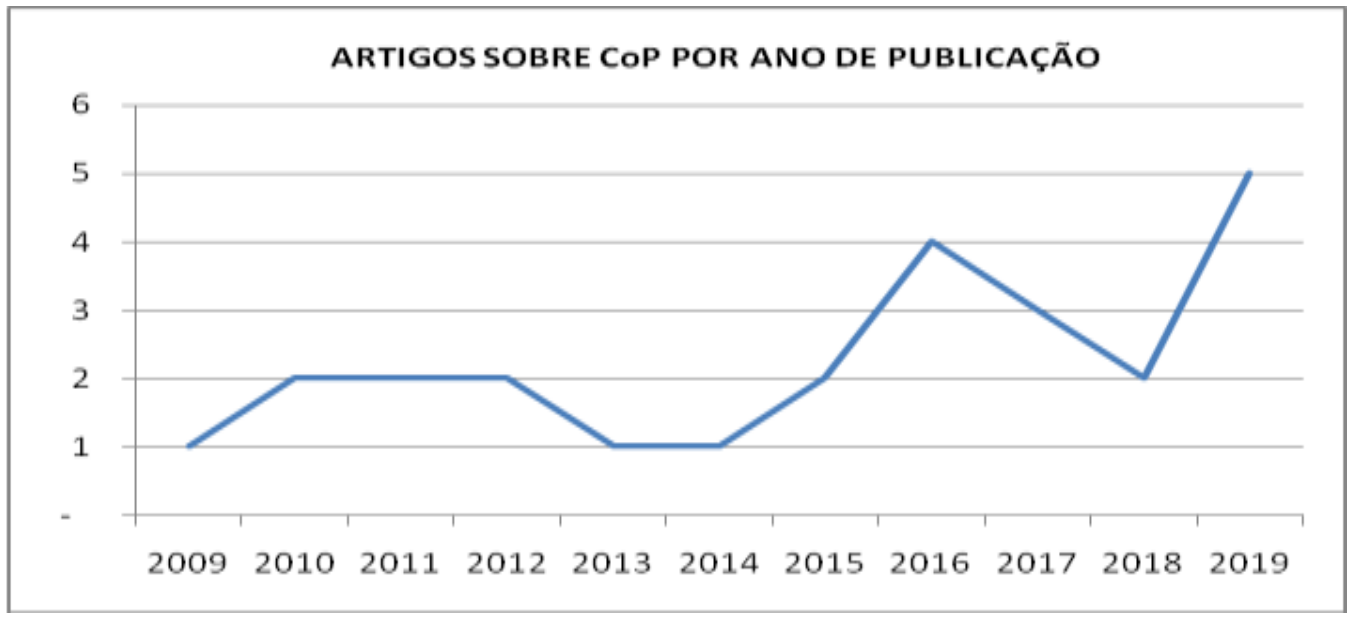

Fonte: Dados da Pesquisa, 2019.

Em relação à quantidade de publicação por ano, 2019 foi o que atingiu o maior número com cinco publicações; em 2018 houve duas publicações; o ano de 2017 obteve três publicações; em 2016 foram quatro publicações, os demais anos receberam entre uma e três publicações, cada ano.

A partir do Gráfico 2, é possível compreender que há uma linearidade em relação às pesquisas sobre comunidade de prática na Ciência da Informação pelo fato de que, em todos os anos, encontraram-se publicações em formato de artigo científico ou em comunicação científica indexados pela BRAPCl. Esses achados demonstram que a temática é considerada relevante pelos pesquisadores, uma vez que são debruçados esforços para a realização de pesquisas presentes em todos os anos, conforme recorte temporal da pesquisa.

É importante destacar também que foram encontrados na produção analisada 52 (cinqüenta e dois) autores e coautores que publicaram a respeito de comunidades de práticas, nos últimos 10 anos. Esses achados mostram o interesse dos pesquisadores acerca da temática abordada na pesquisa. Além disso, o crescimento no número das pesquisas nos últimos quatro anos evidencia que essa temática vem sendo discutida cada vez mais por pesquisadores e profissionais na Ciência da Informação.

Para a análise de redes sociais, os dados foram dispostos numa matriz no software Excell para atender aos pré-requisitos utilizados no ambiente do software Ucinet gerando como resultado, o grafo abaixo que apresenta a relação existente entre autores e coautores que exploram a temática comunidade de prática na ciência da informação, conforme Figura 1.

Figura 1: Grafo da rede de autoria e coautoria de publicações sobre CoP

Perspectivas em Gestão \& Conhecimento, João Pessoa, v. 10, número especial, p. 88-107, mar. 2020. 


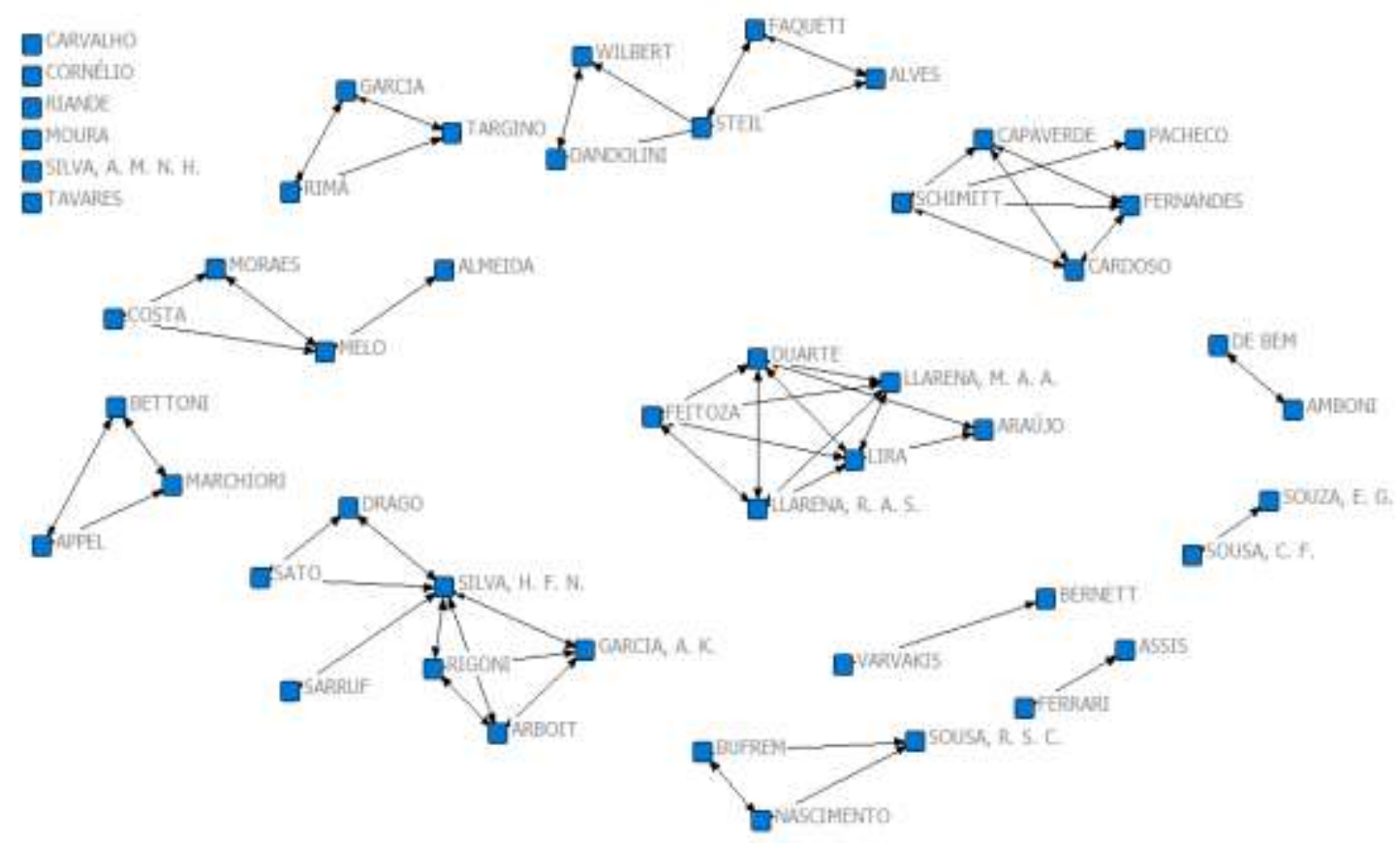

Fonte: Dados da Pesquisa, 2019.

Percebem-se as relações de colaboração existentes entre autores e coautores das publicações em análise, conforme figura 1. Entre Duarte e Lira, uma vez que publicaram juntas, bem como com: Llarena, R. A. S., Llarena, M. A. A. e Feitoza, além de publicarem também com Araújo. Existe colaboração entre os integrantes: Silva, H. F. N. e Sarruf, bem como a primeira com Drago e Sato; e com Rigoni, Garcia, A. K. e Arboit. O autor Melo publicou junto com Almeida, bem como com Costa e Moraes. Já Steil publicou com Faqueti e Alves; bem como com Wilbert e Dandolini. E Schimitt publicou com Pacheco, e também com Fernandes, Cardoso e Capaverde.

Outras relações de autoria e coautoria podem ser vistas com: Sousa, C. F. e Souza, E. G.; Rimá, Garcia, J. C. e Targino; Ferrari e Assis; Marchiori, Appel e Betoni; Souza, R., Bufrem e Nascimento; De Bem e Amboni; e Bernett com Varvakis.

No universo de 25 publicações recuperadas na BRAPCl, foram identificados 59 autores e coautores nas produções individuais, incluindo artigos científicos e comunicações científicas, sendo seis destes com mais de uma publicação, conforme relacionado no Quadro 2. Portanto, na pesquisa, excluindo-se as repetições, foram identificados 52 diferentes autores.

Quadro 2 - Indicadores de produtividade sobre comunidades de práticas na Ciência da Informação

\begin{tabular}{|c|c|}
\hline AUTOR & QUANTIDADE DE PUBLICAÇÕES \\
\hline DUARTE, E. N. & 3 \\
\hline LIRA, S. L. & 3 \\
\hline SILVA, H. F. N. & 3 \\
\hline MELO, E. S. & 2 \\
\hline STEIL, A. V. & 2 \\
\hline SCHIMITT, S. R. & 2 \\
\hline
\end{tabular}

Fonte: Dados da Pesquisa, 2019.

Perspectivas em Gestão \& Conhecimento, João Pessoa, v. 10, número especial, p. 88-107, mar. 2020. 
Os textos apresentados demonstram que a temática comunidade de prática está em pleno desenvolvimento, com abordagens em organizações de diversos setores como, por exemplo, academias, grupos de pesquisa, bibliotecas e outros espaços de informação. Essa crescente produção científica contribui com o fortalecimento da gestão do conhecimento e a evolução na área da Ciência da Informação.

\section{CONCLUSÕES}

A construção do conhecimento tem sido efetivada sob diversas perspectivas, principalmente por meio da utilização de recursos tecnológicos, informacionais e, sobretudo, no compartilhamento de conceitos e ideias entre os saberes. A comunidade de prática vem desempenhando um papel importante quando se trata de gestão do conhecimento, por agrupar idéias e conceitos no campo da Ciência da Informação.

Na Ciência da Informação, a produção científica acerca da comunidade de prática vem sendo discutida pelos autores da área, conforme apontado nesse estudo e, ao mesmo tempo, vem contornando essa prática como importante estratégia em relação à implementação da gestão do conhecimento, pelo crescente numero de publicações sobre a temática. Isso mostra um amadurecimento da comunidade de prática, enquanto modelo de implantação da gestão do conhecimento no campo científico da Ciência da Informação.

Pode-se observar que a investigação alcançou o objetivo proposto de analisar a comunicação científica em relação a comunidades de prática no campo da gestão do conhecimento na área da Ciência da Informação. Houve publicação sobre a temática em todos os anos abrangidos pela pesquisa, com crescimento no número de publicações nos últimos anos. Destaca-se que apesar de o universo de busca ter sido de 10 anos, os números de publicações indexados na base de dados $\mathrm{BRAPCl}$ apresenta certa evolução, já que este tema é cada vez mais emergente no âmbito da GC, como uma prática a ser adotada nas organizações que se preocupam com o compartilhamento de conhecimentos.

Ao analisar a produção científica percebe-se que há um comportamento de expansão da temática sobre o campo, entretanto, é preciso que haja um aprofundamento das discussões no sentido de identificar, principalmente, correntes teórico-metodológicas de abordagens e, também, escolas onde se situam os principais estudos em nível micro e macro. A pesquisa evidenciou a discussão nas revistas científicas da área, sendo necessária uma análise mais aprofundada acerca dos Programas de Pós-Graduação, uma vez que, a Ciência da Informação é construída nesse espaço no Brasil.

Os textos trazem estudos relevantes quanto à utilização de comunidade de prática como estratégia de gestão do conhecimento, o que pode auxiliar no processo de aprendizagem, com contribuições para a construção do conhecimento, favorecendo ambientes propícios ao desenvolvimento da gestão do conhecimento.

Ao longo da análise percebe-se que 16 periódicos publicaram sobre a temática, com um Qualis representativo na área, identificados por A1 e B1 em sua maioria, bem como que dos 52 pesquisadores, seis se dedicaram a publicar mais vezes sobre o tema. Outro fator relevante desvendado na pesquisa é que as comunicações encontradas são, em maior parte; oriundas de estudos colaborativos, ou seja, com mais de um autor, apontando como característica dessa temática o estudo realizado em colaboração. Apenas $8 \%$ dos autores dos textos pesquisados sobre esse tema realizaram publicações individualmente.

Pode-se atribuir como limitação para a pesquisa, o início apenas a partir de 2019 da indexação, pela BRAPCI, das comunicações científicas em eventos da área de ciência da informação. Uma vez que podem ser observados nos Programas de Pós-Graduação que a temática comunidade de prática já vem sendo explorada ao longo dos últimos anos, este fator

Perspectivas em Gestão \& Conhecimento, João Pessoa, v. 10, número especial, p. 88-107, mar. 2020. 
foi um limitador da presente pesquisa, porém, poderá ser objeto de pesquisa futura, a inserção destas comunicações, para melhor abrangência da temática comunidade de prática no campo da gestão do conhecimento na área de ciência da informação.

\section{REFERÊNCIAS}

ÁLVARES, L. M. A. R. Telecentros de informação e negócios como veículo de educação corporativa nas microempresas e empresas de pequeno porte. 2010. $273 \mathrm{f}$. Tese (Doutorado em Ciência da Informação) - Universidade de Brasília, Brasília, 2010.

ARAÚJO, C. A. Á. O que é Ciência da Informação. Belo Horizonte: KMA, 2018.

ARAÚJO, C. A. Á. Fundamentos da ciência da informação: Correntes teóricas e o conceito de informação. Perspectivas em Gestão \& Conhecimento, João Pessoa, v. 4, p. 57-79, 2014. Disponível em: https://periodicos.ufpb.br/ojs2/index.php/pgc/article/view/19120/10827. Acesso em: 8 dez. 2019.

BASE DE DADOS EM CIÊNCIA DA INFORMAÇÃO (BRAPCI, 1972-2020). Disponível em: http://www.brapci.inf.br/. Acesso em: 8 dez. 2019.

BETTENCOURT, M. P. L.; CIANCONI, R. B. Gestão do conhecimento: um olhar sob a perspectiva da Ciência da Informação. Revista Tendências da Pesquisa Brasileira em Ciência da Informação, Brasília, DF, v. 5, n. 1, 2012.

BROOKES, B. C. The foudations of information science. Journal of Information Science, Amsterdã, v. 2, n. 3-4, p. 125-133, 1980.

DUARTE, E. N. Redes temáticas para cooperação em gestão da informação e do conhecimento. João Pessoa: Editora da UFPB. 2015. 154p.

DUARTE E. N.; LIRA, S. L.; LIRA, W. S. Gestão do conhecimento: origem, evolução, conceitos e ações. In: DUARTE, E. N.; LLARENA, R. A. S.; LIRA, S. L. (Org.). Da informação à auditoria de conhecimento: a base para a inteligência organizacional. João Pessoa: PB, Editora UFPB, 2014.

DUARTE, E. N. et al. Grupo de pesquisa e aprendizagem como comunidade de prática e de interesse. In: DUARTE, E. N. et al. (org.). Enfoques multidisciplinares da gestão do conhecimento. João Pessoa. Editora UFPB, 2019.

GARCIA, L. G. Elaboração e implementação piloto de um portal para o apoio à cooperação científica e tecnológica e sua aplicação à área de tratamento de superfícies metálicas. 2005. 175f. Tese (Doutorado em Ciência e Engenharia de Materiais) - Universidade Federal de São Carlos, São Paulo, 2005.

GUTIERREZ, M. PEREZ-MONTORO. Gestión del conocimiento en las organizaciones: Fundamentos, metodologia y praxis. Barcelona: Trea, 2008.

LAVE, J.; WENGER, E. Situated learning: legitimate peripheral participation. Cambridge: Cambridge University Press, 1991.

Perspectivas em Gestão \& Conhecimento, João Pessoa, v. 10, número especial, p. 88-107, mar. 2020. 
LIRA, S. L. Modelo de comunidade de prática com foco em gestão do conhecimento no ambiente contábil público de universidades federais brasileiras. 2019. 257 f. Tese (Doutorado em Ciência da Informação) - Universidade Federal da Paraíba, João Pessoa, 2019.

LIRA, S. L.; SILVA, E. B. F.; LLARENA, R. A. S.; DUARTE, E. N. Colaboração na produção científica em grupo de pesquisa. In: Encuentro Ibérico de la Asociación de Educación e Investigación en Ciencia de la Información de Iberoamérica y el Caribe (EDICIC), 8., 2017. Anais [...]. Universidade de Coimbra, Portugal, 2017.

NAKANO, D. N.; FLEURY, A. C. C. Conhecimento Organizacional: uma revisão conceitual de modelos e quadros de referências. Produto \& Produção, v. 8, n. 2, 2005. Disponível em: https://seer.ufrgs.br/ProdutoProducao/article/view/3206/1763. Acesso: 8 dez. 2019.

PLATAFORMA SUCUPIRA. Disponível em:

https://sucupira.capes.gov.br/sucupira/public/index.xhtml. Acesso em: 01 dez. 2019.

POPPER, K. R. Conhecimento objetivo. Belo Horizonte: Itatiaia, 1999.

SARACEVIC, T. Information Science. JASIS - Journal of the American Society for Information Science, v. 50, n. 12, p. 1051-1063, 1999.

SARACEVIC, T. Ciência da Informação: origem, evolução e relações. Perspectivas em Ciência da Informação, Belo Horizonte, v. 1, n. 1, p. 41-62, 1996. Disponível em: http://portaldeperiodicos.eci.ufmg.br/index.php/pci/article/view/235/22. Acesso: 8 dez. 2019.

SOUZA, E. D. Gestão da informação e do conhecimento: possibilidades, condições e perspectivas. In: GARCIA, J. C. R.; TARGINO, M. G. Desvendando facetas da gestão e políticas de informação. João Pessoa: EdUFPB, 2015. v. 1, Cap. 1, p. 29-56.

SOUZA, E. D.; DIAS, E. J. W.; NASSIF, M. E. A GESTÃO DA INFORMAÇÃO E DO CONHECIMENTO NA CIÊNCIA DA INFORMAÇÃO: perspectivas teóricas e práticas organizacionais. Informação \& sociedade: estudos, João Pessoa, v. 21, n. 1, p. 55-70, jan./abr. 2011. Disponível em: http://periodicos.ufpb.br/index.php/ies/article/view/4039. Acesso em: 8 dez. 2019.

TARGINO, M. G. Comunicação científica: uma revisão de seus elementos básicos. Informação \& Sociedade: Estudos. v.10, n. 2. 2000.

TEIXEIRA FILHO. J. Comunidades virtuais: como as comunidades de práticas na internet estão mudando os negócios. Rio de Janeiro, SENAC. 2002.

TEIXEIRA FILHO, J. Tudo que parece sólido desmancha no ar: indicadores na gestão do conhecimento. Insight Informal, v. 53, 2002.

VALENTIM, M. L. P. Gestão da informação e gestão do conhecimento em ambientes organizacionais: conceitos e compreensões. Tendências da Pesquisa Brasileira em Ciência da Informação, v. 1, n.1, 2008.

Perspectivas em Gestão \& Conhecimento, João Pessoa, v. 10, número especial, p. 88-107, mar. 2020. 


\section{APÊNDICE A - CORPUS DA PESQUISA}

BERNETT, D.; VARVAKIS, G. Desafios das tecnologias de informação e comunicação sob a perspectiva da gestão do conhecimento na sociedade em redes. DataGramaZero: Revista de Ciência da Informação, Rio de Janeiro, 2010, 11.3.

CARVALHO, M. Recursos educacionais abertos na Universidade Aberta. A rede como estratégia de comunicação e sustentabilidade. Cadernos BAD, 2018, 1: 201-211.

CORNÉLIO, N. A. G.; DE ABREU, A. F.; COSTA, E. O. Espaço interativo: modelo de relação universidade-empresa baseada em comunidades de prática. Ciência da Informação, 2010, 39.1.

DE BEM, R.; AMBONI, N. F. Práticas de gestão do conhecimento: o caso da biblioteca universitária da UFSC. Revista ACB, 2013, 18.1: 736-751.

DE SOUSA, C. F.; DE SOUZA, E. G. Comunidades de prática: aprendizado e compartilhamento de conhecimento entre trabalhadores nas organizações. Em Questão, 2019, 25.2: 348-369.

DE SOUSA, R. S. C.; BUFREM, L. S.; DO NASCIMENTO, B. S. Olhares complementares sobre letramento científico e o papel dos pesquisadores em comunidades virtuais. Em Questão, 2015, 21.3: 271-295.

DRAGO, I.; SILVA, H. F. N.; SATO, K. A. S. Contribuições do Movimento Nós Podemos Paraná para a criação e compartilhamento de conhecimentos. Em Questão, 2014, 20.1: 165-188.

FAQUETI, M. F.; ALVES, J. B. M.; STEIL, A. V. Aprendizagem organizacional em bibliotecas acadêmicas: uma revisão sistemática. Perspectivas em Ciência da Informação, 2016, 21.4: 156-179.

FERNANDES, F. R. et al. Comunidades de prática: uma revisão bibliográfica sistemática sobre casos de aplicação organizacional. Atoz: novas práticas em informação e conhecimento, 2016, 5.1: 44-52.

FERRARI, É.; ASSIS, J. A dimensão informacional da transição capilar: identidade e empoderamento nas mídias sociais. Revista Brasileira de Educação em Ciência da Informação, 2017, 4.1: 74-95.

LIRA, S. L.; ARAÚJO, W. J.; DUARTE, E. N. Cenários prospectivos para implantação de Comunidades de prática em unidades de Contabilidade em universidades públicas. Perspectivas em Gestão \& Conhecimento, 2017, 7.1: 170-190.

LIRA, S. L.; DUARTE, E. N. Comunidade de prática como estratégia de Gestão do conhecimento na contabilidade pública de Universidades Federais do Brasil. In: XX Encontro Nacional de Pesquisa em Ciência da Informação (XX ENANCIB). 2019.

LLARENA, M. A, A.; LLARENA, R. A. S.; DUARTE, E. N.; LIRA, S. L.; FEITOZA, R. A. B. A construção do conhecimento por meio da aprendizagem colaborativa. In: XX Encontro Nacional de Pesquisa em Ciência da Informação (XX ENANCIB). 2019.

Perspectivas em Gestão \& Conhecimento, João Pessoa, v. 10, número especial, p. 88-107, mar. 2020. 
MARCHIORI, P. Z.; APPEL, A. L.; BETTONI, E. M. A disrupção pervasiva da tecnologia na privacidade e nos processos de aprendizagem. Atoz: novas práticas em informação $e$ conhecimento, 2016, 5.1: 3.

MELO, E. S.; ALMEIDA, M. C. Comunidades de prática: um estudo de caso REDARTE/RJ. Informação@ Profissões, 2015. 4.2: 87-111.

MELO, E. S.; MORAES, M. G.; COSTA, M. A. Características de comunidades de prática existentes no Serviço de Informação em Arte: o caso da REDARTE/RJ. Perspectivas em Ciência da Informação, 2019, 24.2: 3-13.

MOURA, M. A. Informação e conhecimento em redes virtuais de cooperação científica: necessidades, ferramentas e usos. DataGramaZero: Revista de Ciência da Informação, 2009, 10.2: 141-155.

RIANDE, G. D. i Únete! Humanidades Digitales y cultura del asociacionismo| Juntemo-nos! Humanidades Digitais e cultura do associacionismo| Join us! Digital Humanities and association culture. Liinc em Revista, 2019, 15.1.

RIMÁ, J. C.; GARCIA, J. C. R.; TARGINO, M. G. Comunidades de práticas virtuais dos técnicos administrativos em educação de Instituições de Ensino Superior. Informação em Pauta, 2017, 2.1: 8-27

SARRUF, P. G.; SILVA, H. F. N. Comunidades de prática virtuais e a troca e criação de conhecimentos em micro e pequenas empresas. DataGramaZero: Revista de Ciência da Informação, Rio de Janeiro, 2012, 13.1.

SCHMITT, S. R.; PACHECO, A. S. V. Fatores críticos de sucesso à manutenção de comunidades de prática: análise sob a ótica de um grupo de gestores com características preponderantes as de uma comunidade. P2P \& Inovação, 2016, 2.2: 115-141.

SILVA, A. M. N. H. Viabilidade de implementação de comunidades de prática (COP) para a gestão e compartilhamento da informação na Biblioteca Central do UNIPÊ. Informação \& Sociedade, 2011, 21.2.

SILVA, H. F. N. et al. As contribuições relativas ao uso de eventos/fóruns para constituição de comunidades de práticas e expressão da inteligência coletiva: o caso do Bibliocontas. Perspectivas em Ciência da Informação, 2012, 17.3: 100-120.

TAVARES, M. G. P. Informação, aprendizagem e criação do conhecimento em comunidades de prática: um estudo de caso. Revista iberoamericana de educación. Belo Horizonte: UFMG, 2011.

WILBERT, J. K. W.; DANDOLINI, G.; STEIL, A. V. Transformações conceituais de comunidades de prática: da aprendizagem situada à gestão organizacional. Perspectivas em Gestão \& Conhecimento, 2018.

Artigo recebido em 09/12/2019 e aceito para publicação em 16/03/2020

Perspectivas em Gestão \& Conhecimento, João Pessoa, v. 10, número especial, p. 88-107, mar. 2020. 